\title{
A Zinc Coordination Polymer Sensor for Selective and Sensitive Detection of Doxycycline Based on
}

\section{Fluorescence Enhancement}

Ahui Sun,,$^{\dagger}$ Yonghang Yang, ${ }^{\dagger}$ Yanfeng Liu,,${ }^{* \dagger}$ Lu Ding,,${ }^{\dagger}$ Pan Duan,,$^{\dagger}$ Weiting Yang,,${ }^{*}+$ Qinhe $\operatorname{Pan}^{*}+$

$\dagger$ Key Laboratory of Advanced Materials of Tropical Island Resources, Ministry of Education, School of Chemical Engineering and Technology Hainan University, Haikou, Hainan, 570228, China. 


\section{CONTENTS}

Table S1. The details of the 13 antibiotics

Figure S1. The particle size distribution of HNU-55 suspension.

Figure S2. The TGA plot of HNU-55.

Figure S3. The PXRD patterns of HNU-55 for simulated, as-synthesized, after detecting DOX and after five cycles of DOX detection.

Figure S4. The PXRD patterns of HNU-55 for immersed in common organic solvents.

Table S2. Comparison of reported methods for DOX detection.

Figure S5. The detection response time of DOX to HNU-55.

Figure S6. The anti-interference performance of HNU-55 for DOX in the presence of other biological molecules or metal ions.

Figure S7. SEM images of HNU-55 before (a) and after (b) detection of DOX; and TEM images of HNU-55 before (c) and after (d) detection of DOX.

Figure S8. The fluorescence spectra of DOX, HNU-55 and the mixture of HNU-55 and DOX.

Figure S9. The fluorescence spectra of HNU-55 in the presence of DOX $(20 \mu \mathrm{M})$, OTC (40 $\mu \mathrm{M})$ and TET (40 $\mu \mathrm{M})$ under optimal conditions, respectively.

Figure S10. The full XPS spectra of DOX, HNU-55 and DOX@HNU-55.

Figure S11. The UV-Vis spectra of DOX, HNU-55 and the mixture of HNU-55 and DOX. 
Table S1. The details of the 13 antibiotics

\begin{tabular}{|c|c|c|}
\hline Entry & Name & Chemical structure \\
\hline 1 & $\begin{array}{l}\text { nitrofurantoin } \\
\qquad \text { (FUT) }\end{array}$ & \\
\hline 2 & $\begin{array}{l}\text { furazolidone } \\
\text { (FUZ) }\end{array}$ & \\
\hline 3 & $\begin{array}{l}\text { roxithromycin } \\
\qquad(\mathrm{ROX})\end{array}$ & \\
\hline 4 & $\begin{array}{c}\text { Thiamphenicol } \\
\text { (THI) }\end{array}$ & \\
\hline 5 & $\begin{array}{c}\text { oxytetracycline } \\
\text { hydrochloride (OTC) }\end{array}$ & $\mathrm{HCl}$ \\
\hline 6 & $\begin{array}{c}\text { tetracycline } \\
\text { hydrochloride (TET) }\end{array}$ & $\mathrm{HCl}^{\mathrm{OH}}$ \\
\hline
\end{tabular}




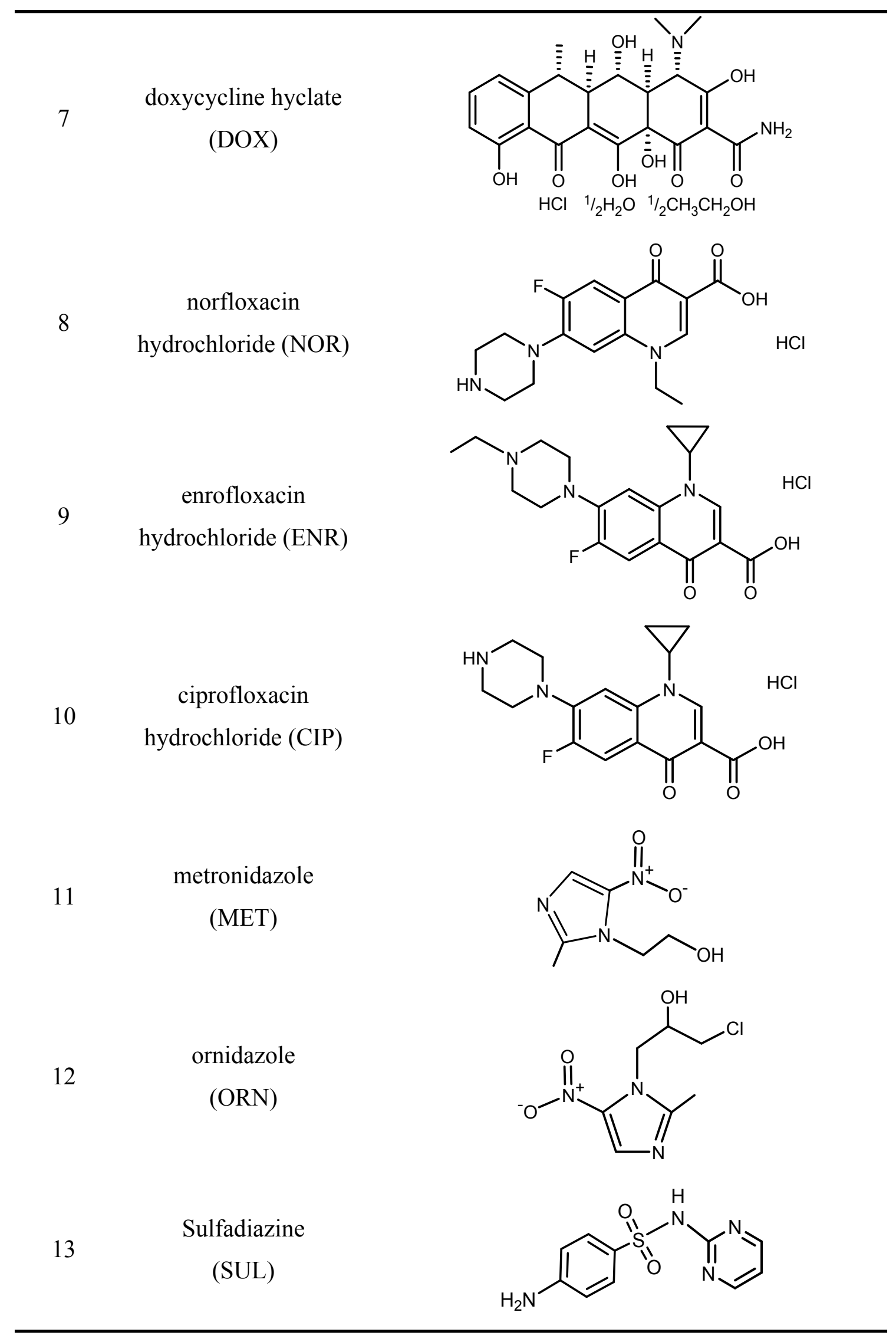




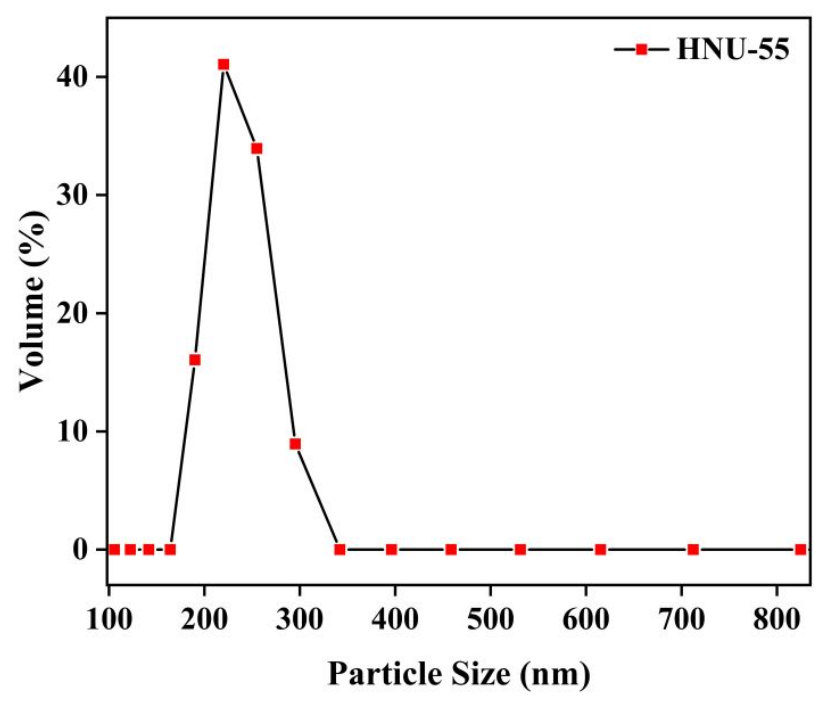

Figure S1. The particle size distribution of HNU-55 suspension.

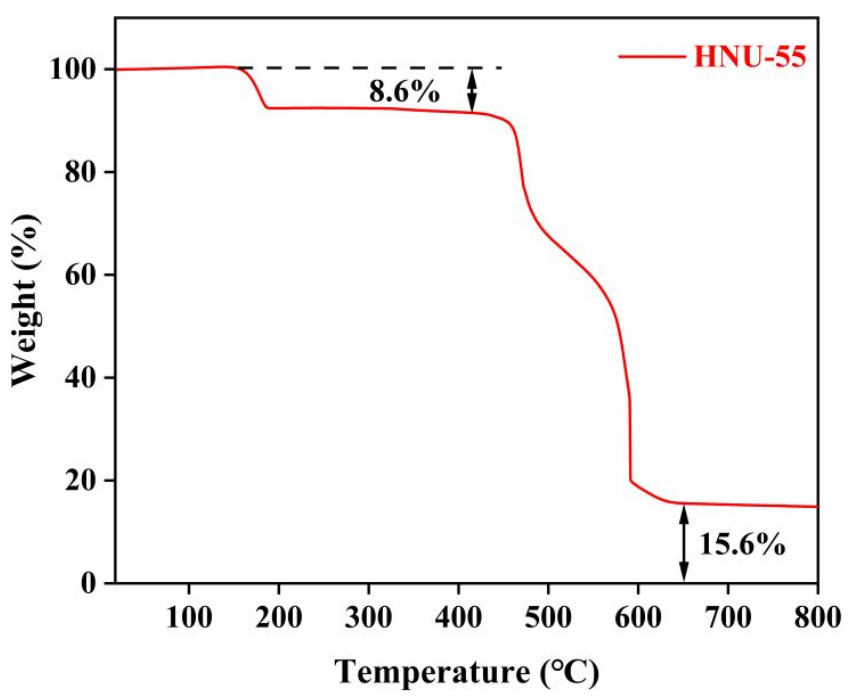

Figure S2. The TGA plot of HNU-55. 


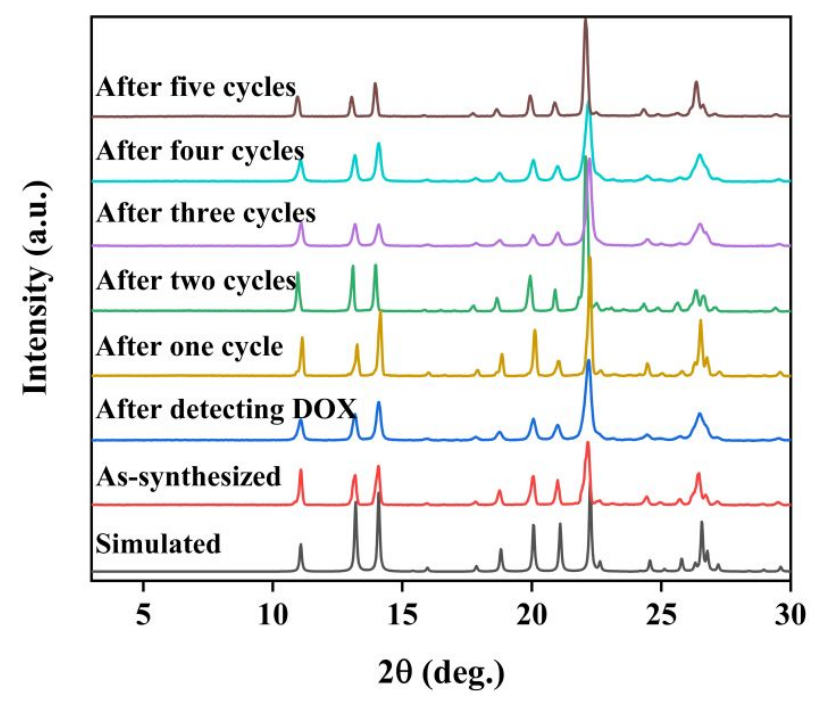

Figure S3. The PXRD patterns of HNU-55 for simulated, as-synthesized and after each recycling experiment of DOX detection.

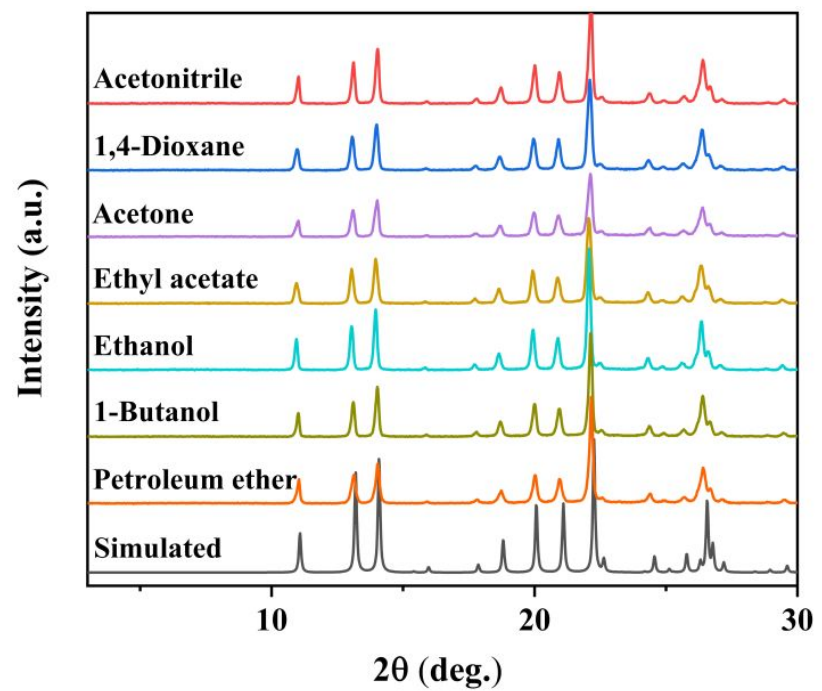

Figure S4. The PXRD patterns of HNU-55 for immersed in common organic solvents. 
Table S2. Comparison of reported methods for DOX detection.

\begin{tabular}{|c|c|c|c|c|}
\hline Methods & Materials & Linear range & LOD & $\overline{\text { Ref. }}$ \\
\hline UV-Vis & - & $0.5-35 \mathrm{mg} / \mathrm{L}$ & $0.24 \mathrm{mg} / \mathrm{L}$ & [1] \\
\hline ELISA & - & $0.01-100 \mathrm{ng} / \mathrm{mL}$ & $0.14 \mathrm{ng} / \mathrm{g}$ & [2] \\
\hline LC-UV & - & - & $10 \mu \mathrm{g} / \mathrm{kg}$ & {$[3]$} \\
\hline LC-MS/MS & - & - & $1 \mu \mathrm{g} / \mathrm{kg}$ & [3] \\
\hline Colorimetric assay & Au nanoparticles & $0.42-21 \mu \mathrm{g} / \mathrm{mL}$ & $20 \mathrm{ng} / \mathrm{mL}$ & [4] \\
\hline Colorimetric & $\begin{array}{l}\mathrm{Fe}_{3} \mathrm{O}_{4} \text { magnetic } \\
\text { nanoparticles }\end{array}$ & $0.050-1 \mu \mathrm{M}$ & $48 \mathrm{nM}$ & [5] \\
\hline Electrochemistry & - & $50-500 \mu \mathrm{M}$ & $4.35 * 10^{4} \mathrm{nM}$ & [6] \\
\hline Fluorometry & BNQD-Eu ${ }^{3+}$ & $2.5-50 \mu \mathrm{M}$ & $28 \mathrm{nM}$ & [7] \\
\hline Fluorometry & $\begin{array}{l}\mathrm{CDs@MOF}(\mathrm{Eu}) \text { hybrid } \\
\text { material }\end{array}$ & $0-60 \mu \mathrm{M}$ & $360 \mathrm{nM}$ & [8] \\
\hline Fluorometry & 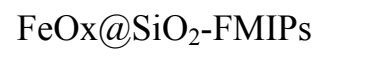 & $0.2-6 \mu \mathrm{M}$ & $117 \mathrm{nM}$ & [9] \\
\hline Fluorometry & $\mathrm{NH}_{2}$-MIL-53(Al) & $0-66.67 \mu \mathrm{M}$ & $40.36 \mathrm{nM}$ & [10] \\
\hline Fluorometry & Eu-in-BTEC & $0-6 \mu \mathrm{M}$ & $47 \mathrm{nM}$ & [11] \\
\hline Fluorometry & S,N-CDs & $0.1-100 \mu \mathrm{M}$ & $25 \mathrm{nM}$ & [12] \\
\hline Fluorometry & $\mathrm{Zn}(\mathrm{PSA})_{2}\left(\mathrm{H}_{2} \mathrm{O}\right)_{2}$ & $0-30 \mu \mathrm{M}$ & $3.7 \mathrm{nM}$ & This Work \\
\hline
\end{tabular}




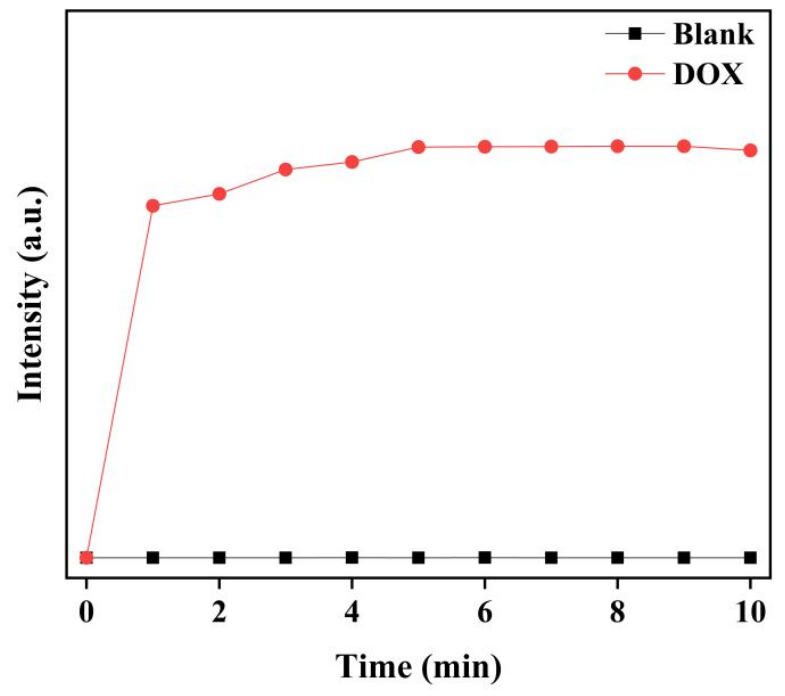

Figure S5. The detection response time of DOX to HNU-55.

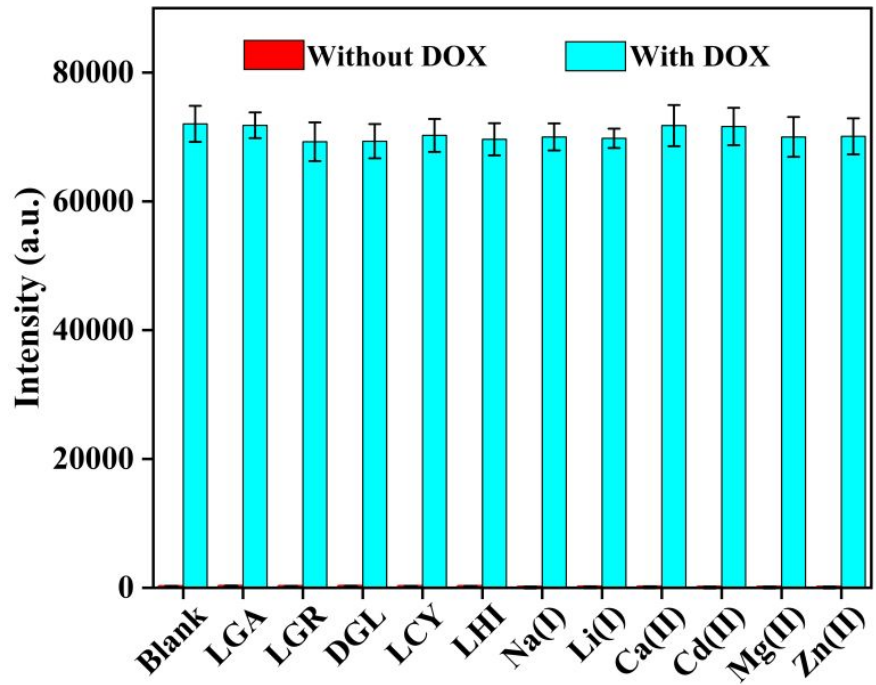

Figure S6. The anti-interference performance of HNU-55 for DOX in the presence of other biological molecules or metal ions. 

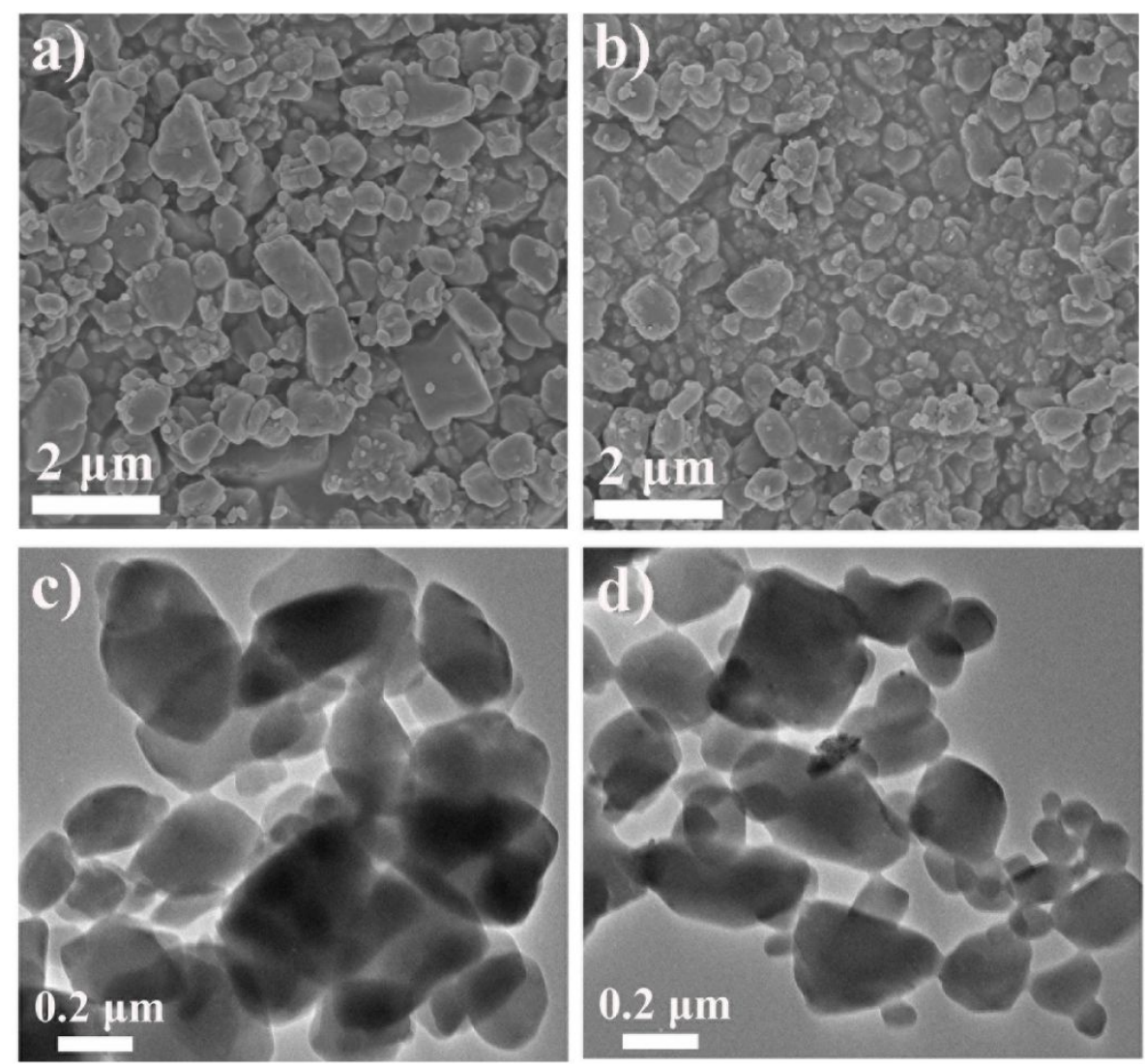

Figure S7. SEM images of HNU-55 before (a) and after (b) detection of DOX; and TEM images of HNU-55 before (c) and after (d) detection of DOX. 




Figure S8. The fluorescence spectra of DOX, HNU-55 and the mixture of HNU-55 and DOX.



Figure S9. The fluorescence spectra of HNU-55 in the presence of DOX $(20 \mu \mathrm{M})$, OTC (40 $\mu \mathrm{M})$ and TET $(40 \mu \mathrm{M})$ under excitation at $390 \mathrm{~nm}$, respectively. 




Figure S10. The full XPS spectra of DOX, HNU-55 and DOX@HNU-55.

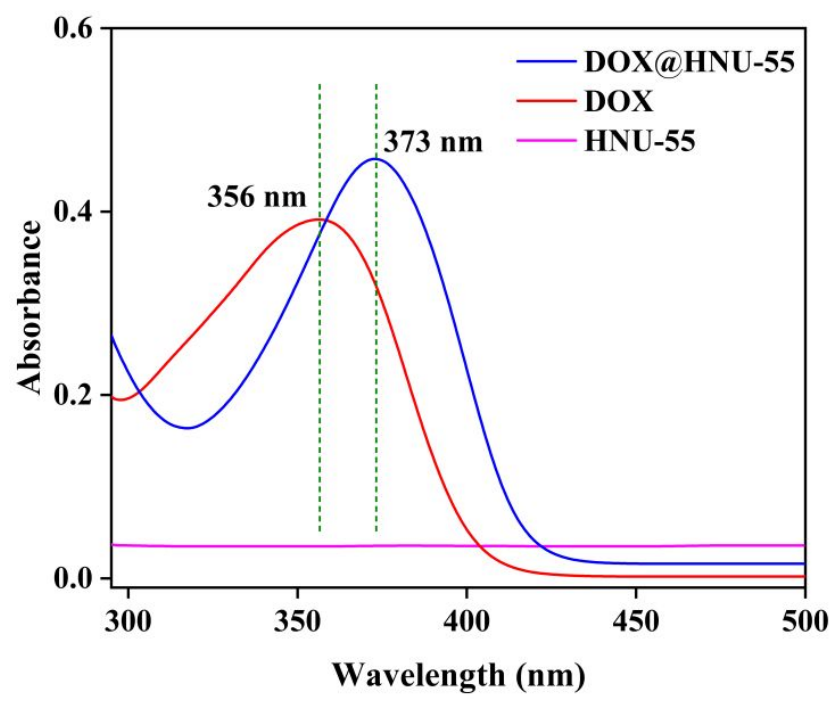

Figure S11. The UV-Vis spectra of DOX, HNU-55 and the mixture of HNU-55 and DOX. 


\section{REFERENCES}

(1) Abdulsattar, J. O.; Hadi, H.; Richardson, S.; Iles, A.; Pamme, N., Detection of doxycycline hyclate and oxymetazoline hydrochloride in pharmaceutical preparations via spectrophotometry and microfluidic paper-based analytical device ( $\mu$ PADs). Anal. Chim. Acta. 2020, 1136, 196-204.

(2) Le, T.; Zhao, Z. W.; Wei, W.; Bi, D. R., Development of a highly sensitive and specific monoclonal antibody-based enzyme-linked immunosorbent assay for determination of doxycycline in chicken muscle, liver and egg. Food Chem. 2012, 134, 2442-2446.

(3) Gajda, A.; Posyniak, A.; Zmudzki, J.; Tomczyk, G., Determination of doxycycline in chicken fat by liquid chromatography with UV detection and liquid chromatography-tandem mass spectrometry. J Chromatogr. B Analyt. Technol. Biomed. Life Sci. 2013, 928, 113-120.

(4) Shen, L.; Chen, J.; Li, N.; He, P. L.; Li, Z., Rapid colorimetric sensing of tetracycline antibiotics with in situ growth of gold nanoparticles. Anal. Chim. Acta. 2014, 839, 83-90.

(5) Wang, Y. L.; Sun, Y. J.; Dai, H. C.; Ni, P. J.; Jiang, S.; Lu, W. D.; Li, Z.; Li, Z., A colorimetric biosensor using $\mathrm{Fe}_{3} \mathrm{O}_{4}$ nanoparticles for highly sensitive and selective detection of tetracyclines. Sens. Actuators B Chem. 2016, 236, 621-626.

(6) Gurler, B.; Ozkorucuklu, S. P.; Kir, E., Voltammetric behavior and determination of doxycycline in pharmaceuticals at molecularly imprinted and non-imprinted overoxidized polypyrrole electrodes. J Pharm. Biomed. Anal. 2013, 84, 263-268.

(7) Yang, K. R.; Jia, P.; Hou, J. J.; Bu, T.; Sun, X. Y.; Liu, Y. N.; Wang, L., Innovative dualemitting ratiometric fluorescence sensor for tetracyclines detection based on boron nitride quantum dots and europium ions. ACS Sustain. Chem. Eng. 2020, 8, 17185-17193.

(8) Fu, X.; Lv, R.; Su, J.; Li, H.; Yang, B. Y.; Gu, W.; Liu, X., A dual-emission nano-rod MOF equipped with carbon dots for visual detection of doxycycline and sensitive sensing of $\mathrm{MnO}_{4}^{-} \cdot$ RSC Adv. 2018, 8, 4766-4772. 
(9) Ashley, J.; Feng, X. T.; Sun, Y., A multifunctional molecularly imprinted polymer-based biosensor for direct detection of doxycycline in food samples. Talanta 2018, 182, 49-54.

(10) Li, C. H.; Zhu, L.; Yang, W. X.; He, X.; Zhao, S. L.; Zhang, X. S.; Tang, W. Z.; Wang, J. Z.; Yue, T. L.; Li, Z. H., Amino-Functionalized Al-MOF for fluorescent detection of tetracyclines in milk. J. Agric. Food Chem. 2019, 67, 1277-1283.

(11) Yu, L.; Chen, H. X.; Yue, J.; Chen, X. F.; Sun, M. T.; Hou, J.; Alamry, K. A.; Marwani, H. M.; Wang, X. K.; Wang, S. H., Europium metal-organic framework for selective and sensitive detection of doxycycline based on fluorescence enhancement. Talanta 2020, 207, 120297-12304.

(12) Song, J. P.; Li, J.; Guo, Z. Y.; Liu, W.; Ma, Q.; Feng, F.; Dong, C., A novel fluorescent sensor based on sulfur and nitrogen co-doped carbon dots with excellent stability for selective detection of doxycycline in raw milk. RSC $A d v . \mathbf{2 0 1 7}, 7,12827-12834$. 